\title{
Proceeding
}

Supplementary Issue: Rio 2016 Olympic Games Third Anniversary Special Edition. Olympic Studies Forum, 2-3 September 2019. Federal University of Sergipe, Aracaju, Brazil

\section{Rio 2016 Paralympic athletes on digital social networks}

\section{Os atletas Paralímpicos Rio 2016 nas redes sociais digitais}

\author{
CARLOS TEIXEIRA $\triangle$, FERNANDA TORRES FAGGIANI, ALESSANDRA MARIA SCARTON
}

Research Group in Olympic Studies, Pontifical Catholic University of Rio Grande do Sul, Brazil

\begin{abstract}
The objective of this research was to analyze how the participation of Brazilian Paralympic athletes in the Rio 2016 Games influenced the development of their digital social networks until the Parapan-American Games Lima 2019, focusing specifically on Facebook, Instagram and Twitter. The study was of a quantitative and descriptive nature. The sample included 26 Brazilian athletes. The main findings of the research were that for Paralympic athletes the network that presented the highest growth potential was Facebook. In addition, most participants represent the most popular Paralympic modalities in Brazil: swimming and athletics. It is also noteworthy that athletes with physical disabilities are the most active in social networks when compared with visual and intellectual. The movement of social networks in the context of Paralympic athletes was explored, and considerations that may contribute to the qualification and greater reach of these tools in the Paralympic context as a means of forming a sports culture more qualified. Keywords: Paralympic Games; Social media; Athletes.
\end{abstract}

Cite this article as:

Teixeira, C., Faggiani, F.T., \& Scarton, A.M. (2020). Rio 2016 Paralympic athletes on digital social networks (in Portuguese). Journal of Human Sport and Exercise, 15(1proc), S36-S45. doi:https://doi.org/10.14198/jhse.2020.15.Proc1.05

Corresponding author. Avenida Ipiranga, 6681 - Prédio 7 - Secretaria. Bairro: Jardim Botânico 90.610-900 cidade: Porto Alegre, RS - Brasil. https://orcid.org/0000-0001-6829-1682

E-mail: eu@ocarlosteixeira.com.br

Supplementary Issue: Rio 2016 Olympic Games Third Anniversary Special Edition. Olympic Studies Forum, 2-3 September 2019. Federal University of Sergipe, Aracaju, Brazil.

JOURNAL OF HUMAN SPORT \& EXERCISE ISSN 1988-5202

(c) Faculty of Education. University of Alicante

doi:10.14198/jhse.2020.15.Proc1.05 


\section{RESUMO}

O objetivo dessa pesquisa foi analisar como a participação dos atletas Paralímpicos brasileiros nos Jogos Rio 2016 influenciou o desenvolvimento de suas redes sociais digitais até os Jogos Parapan-Americanos Lima 2019, focando especificamente no Facebook, Instagram e Twitter. 0 estudo foi de cunho quantitativo e descritivo. Participaram da amostra 26 atletas brasileiros. Os principais achados da pesquisa foram que para os atletas paralímpicos a rede que apresentou maior potencial de crescimento foi o Facebook. Além disso, a maioria dos participantes representa as modalidades Paralímpicas mais populares no Brasil: natação e atletismo. Também se destaca que os atletas com deficiência física são os mais atuantes em redes sociais quando comparados com a deficiência visual e intelectual. Explorou-se o movimento das redes sociais no contexto de atletas paralímpicos e indicou-se considerações que podem contribuir para a qualificação e um maior alcance dessas ferramentas no contexto Paralímpico como meio de formação de uma cultura paradesportiva mais qualificada. Palavras-chaves: Jogos Paralímpicos; Redes Sociais; Atletas. 


\section{INTRODUÇÃO}

Os Jogos Paralímpicos 2016 foram disputados entre os dias 7 e 18 de setembro de 2016 na cidade do Rio de Janeiro, com a participação de 4.328 atletas de 159 países disputando 528 eventos de 22 esportes diferentes (Comitê Paralímpico Internacional, 2016). A delegação brasileira foi a maior da história dos Jogos Paralímpicos contando pela primeira vez com representantes em todas as 22 modalidades do programa Paralímpico, totalizando 278 atletas (Comitê Paralímpico Brasileiro, 2016). O Brasil encerrou a competição na oitava colocação geral com 72 medalhas, sendo 14 de ouro, 29 de prata e 29 de bronze.

O esporte Paralímpico caracteriza-se por um ambiente restrito englobando ao todo 25 modalidades, sendo 20 de verão e cinco de inverno. Além disso, acrescenta-se uma maior restrição em função do processo de classificação esportiva, realizada por uma equipe médica credenciada e que permite a classificação funcional ou médica (Mello; Winckler; 2012). A partir dessa classificação, determina-se quem são os atletas elegíveis ou inelegíveis para a prática das modalidades. Percebe-se, portanto, que o esporte Paralímpico não é acessível a todos, sendo necessário características mínimas de deficiência indicadas pela classificação funcional. São elegíveis nos Jogos Paralímpicos as deficiências física, visual e intelectual. A deficiência física considera o indivíduo que apresenta qualquer comprometimento no aparelho locomotor, como paralisia cerebral, amputação e lesão medular. A deficiência visual caracteriza-se pelo comprometimento que não pode ser compensado por nenhum aparelho em ambos os olhos. E no caso da deficiência intelectual caracteriza-se pelo comprometimento cognitivo e prejuízo no funcionamento adaptativo correspondente a sua fase de desenvolvimento (Mello; Winckler; 2012; Greguol; Costa; 2019).

O esporte para pessoas com deficiência tem seus primeiros relatos no começo do século XX e surge como uma ferramenta de reabilitação, tornando-se palco para 0 alto desempenho apenas no final da década de 1990. Embora 0 alto rendimento seja a manifestação mais conhecida, um fenômeno complexo como 0 esporte não se resume em um ambiente no qual o mais importante seja, simplesmente, ganhar ou perder. Com o movimento Paralímpico tornando-se um fenômeno de grande proporção, por influência do esporte Olímpico, mesmo tendo processos históricos divergentes com relação a origem e desenvolvimento, o esporte Olímpico e Paralímpico podem convergir com relação a manifestação da prática esportiva (Mello; Winckler; 2012; Santos et al., 2019).

A forma como os atletas Paralímpicos caracterizam a importância do esporte na sua vida é legítima e merece atenção. Os atletas a partir de suas próprias percepções, conseguem expressar através do próprio corpo e da sua vida aspectos como a qualidade de vida, a saúde, a inclusão social e a interferências do esporte na sua rotina. Para esses atletas as condições de saúde e de rendimento do esporte vão além de dados estatísticos, pois representam um novo estilo de vida que provoca mudanças pessoais importantes potencializando as suas limitações (Araújo, 2011; Mello; Winckler; 2012).

Dentro do contexto Olímpico e Paralímpico cabe destacar o papel relevante que as redes sociais digitais têm apresentado cultural e socialmente nos dias atuais, principalmente quando associadas aos grandes eventos esportivos. Utilizadas como um meio de comunicação digital para cobertura midiática, divulgação e repercussão, essas redes atingiram um importante patamar como mídia, ampliando significativamente a reverberação dos acontecimentos esportivos. É possível ainda observar a apropriação dessas redes digitais também por parte dos atletas que já as identificaram como um poderoso veículo de divulgação de sua imagem, além da permanente exposição e contato com os mais diversos públicos. O Brasil é um dos países que passa mais tempo por dia utilizando internet e redes sociais, sendo possível considerar Facebook (130 
milhões de usuários no Brasil), Instagram (57 milhões de usuários no Brasil) e Twitter (8 milhões de usuários no Brasil) como algumas das principais plataformas no país (We are social, 2018; 2019).

Observa-se ainda poucos estudos que discutem as relações entre a mídia e o esporte Paralímpico no Brasil (Figueiredo, 2014; Marques et al., 2014; Zoboli et al., 2016; Santos et al., 2019). Objetivo analisar como a participação de atletas Paralímpicos brasileiros nos Jogos Rio 2016 influenciou no desenvolvimento de suas redes sociais digitais até os Jogos Parapan-Americanos 2019 ocorridos em Lima, focando especificamente no Facebook, Instagram e Twitter.

\section{METODOLOGIA}

O presente artigo apresenta um viés prioritariamente quantitativo e descritivo. Os atletas que compuseram a amostra foram selecionados aleatoriamente e por conveniência, onde a partir dos seus resultados nas provas e destaque na mídia passavam a compor o corpus da pesquisa. Desse modo, cabe ressaltar que a data de início das coletas não foi a mesma para todos os atletas, contudo a partir do dia 11 de setembro de 2016 todos os perfis que fizeram parte da pesquisa estavam sendo coletados, totalizando 26 atletas de modalidades individuais.

Cabe ressaltar que todos os perfis analisados eram abertos e referentes a figuras públicas, não ferindo nenhuma questão ética. Foram selecionados apenas atletas de modalidades individuais, buscando assim obter uma representação mais clara do desempenho da rede, tendo em vista que perfis específicos de equipes são pouco utilizados e em esportes coletivos nem todos os atletas, obrigatoriamente, possuem contas oficiais nas plataformas.

A coleta dos dados foi realizada mensalmente, de forma manual, contemplando o período entre os dias 11 de setembro de 2016 (com os Jogos Paralímpicos Rio 2016 já iniciados) e 1 de outubro de 2019 (um mês após o término do Parapan Lima 2019).

\section{RESULTADOS}

A amostra foi composta por 26 atletas de modalidades individuais, sendo em maior número atletas da Natação e Atletismo, tendo, na sua maioria, a deficiência física. Considerando os resultados dos atletas, 0 grupo apresentou 3 medalhistas de ouro, 9 de prata, 4 de bronze e 10 sem medalha. 0 detalhamento dos aspectos mencionados está apresentado no Quadro 1.

Quadro 1. Atletas Selecionados.

\begin{tabular}{|c|c|c|c|c|c|c|c|}
\hline Atleta & Modalidade & $\begin{array}{c}\text { Colocação final } \\
\text { Jogos } \\
\text { Paralímpicos } \\
2016 \\
\end{array}$ & $\begin{array}{l}\text { Colocação } \\
\text { final } \\
\text { Parapan } \\
2019 \\
\end{array}$ & $\begin{array}{c}\text { Tipo de } \\
\text { deficiência }\end{array}$ & Facebook & Instagram & Twitter \\
\hline Alan Fonteles & Atletismo & Prata & $\begin{array}{c}\text { Não } \\
\text { participou }\end{array}$ & Física & $V$ & $\checkmark$ & $\checkmark$ \\
\hline Alex Pires & Maratona & $16^{\circ}$ & $\begin{array}{c}\text { Não } \\
\text { participou }\end{array}$ & Física & $\checkmark$ & $\checkmark$ & $\checkmark$ \\
\hline André Brasil & Natação & Prata & $\begin{array}{c}\text { Não } \\
\text { participou }\end{array}$ & Física & $\checkmark$ & $\checkmark$ & $\checkmark$ \\
\hline Antônio Tenório & Judô & Prata & Bronze & Visual & 0 & $x$ & $x$ \\
\hline Clodoaldo Silva & Natação & Prata & $\begin{array}{c}\text { Não } \\
\text { participou }\end{array}$ & Física & 0 & $\checkmark$ & $\checkmark$ \\
\hline
\end{tabular}




\begin{tabular}{|c|c|c|c|c|c|c|c|}
\hline Daniel Dias & Natação & Ouro & Ouro & Física & $\checkmark$ & $\checkmark$ & $\checkmark$ \\
\hline $\begin{array}{c}\text { Daniel Tavares } \\
\text { Martins }\end{array}$ & Atletismo & Ouro & Ouro & Intelectual & $\checkmark$ & $\checkmark$ & $x$ \\
\hline Edênia Garcia & Natação & Prata & Ouro & Física & $\checkmark$ & $\checkmark$ & $\checkmark$ \\
\hline Fábio Damasceno & Esgrima & $16^{\circ}$ & $\begin{array}{c}\text { Não } \\
\text { participou }\end{array}$ & Física & $\checkmark$ & $x$ & $x$ \\
\hline $\begin{array}{c}\text { Fernando Aranha } \\
\text { Rocha }\end{array}$ & Paratriathlon & $7^{0}$ & $\begin{array}{c}\text { Não } \\
\text { participou }\end{array}$ & Física & $\checkmark$ & 0 & $x$ \\
\hline $\begin{array}{c}\text { Geraldo von } \\
\text { Rosenthal } \\
\end{array}$ & Tiro & $15^{\circ}$ & Ouro & Física & $\checkmark$ & $x$ & $\checkmark$ \\
\hline Jane Karla & Tiro com arco & $8^{\circ}$ & $\begin{array}{c}\text { Não } \\
\text { participou }\end{array}$ & Física & 0 & $x$ & $x$ \\
\hline Joana Neves & Natação & Bronze & Ouro & Física & $\checkmark$ & $\checkmark$ & $x$ \\
\hline $\begin{array}{l}\text { Jovane Silva } \\
\text { Guissone }\end{array}$ & Esgrima & $8^{\circ}$ & $\begin{array}{c}\text { Não } \\
\text { participou }\end{array}$ & Física & $\checkmark$ & $\checkmark$ & $V$ \\
\hline Lucas Prado & Atletismo & $8^{\circ}$ & Ouro & Visual & $\checkmark$ & $\checkmark$ & $x$ \\
\hline $\begin{array}{l}\text { Luis Carlos C. da } \\
\text { Silva }\end{array}$ & Canoagem & Bronze & $\begin{array}{c}\text { Não } \\
\text { participou }\end{array}$ & Física & 0 & $\checkmark$ & $\checkmark$ \\
\hline $\begin{array}{l}\text { Monica da Silva } \\
\text { Santos }\end{array}$ & Esgrima & $16^{\circ}$ & $\begin{array}{c}\text { Não } \\
\text { participou }\end{array}$ & Física & $\checkmark$ & $\checkmark$ & $x$ \\
\hline $\begin{array}{c}\text { Natália Mayara da } \\
\text { Costa }\end{array}$ & Tênis & $16^{\circ}$ & $\begin{array}{c}\text { Não } \\
\text { participou }\end{array}$ & Física & $\checkmark$ & $\checkmark$ & $\checkmark$ \\
\hline Odair Santos & Atletismo & Prata & $\begin{array}{c}\text { Não } \\
\text { participou }\end{array}$ & Visual & $\checkmark$ & $x$ & $x$ \\
\hline Petrúcio Ferreira & Atletismo & Ouro & Ouro & Física & $\checkmark$ & $x$ & $x$ \\
\hline Phelipe Rodrigues & Natação & Bronze & Ouro & Física & $\checkmark$ & $\checkmark$ & $\checkmark$ \\
\hline Shirlene Coelho & Atletismo & Prata & $\begin{array}{c}\text { Não } \\
\text { participou }\end{array}$ & Física & 0 & $\checkmark$ & $x$ \\
\hline $\begin{array}{c}\text { Terezinha } \\
\text { Guilhermina }\end{array}$ & Atletismo & Bronze & $5^{\circ}$ & Visual & $\checkmark$ & $\checkmark$ & $x$ \\
\hline Veronica Almeida & Natação & $16^{\circ}$ & $\begin{array}{c}\text { Não } \\
\text { participou }\end{array}$ & Física & $\checkmark$ & 0 & $x$ \\
\hline Verônica Hipólito & Atletismo & Prata & Prata & Física & $\checkmark$ & $\checkmark$ & $\checkmark$ \\
\hline $\begin{array}{l}\text { Yohansson do } \\
\text { Nascimento }\end{array}$ & Atletismo & Prata & Prata & Física & $\checkmark$ & $\checkmark$ & $x$ \\
\hline
\end{tabular}

Legenda: $\checkmark$ = possui a rede; 0 = possuía a rede, porém foi encerrada durante a coleta; $\mathbf{X}=$ sem rede. Fonte: Elaborado pelos autores.

Ainda sobre os dados do quadro 1 é possível constatar que o Facebook foi a rede mais utilizada, onde todos os 26 atletas possuíam perfil oficial ao início da coleta, sendo que 5 fanpages foram encerradas durante a pesquisa. O Instagram foi a segunda rede mais usada, com 18 perfis oficiais e 2 encerrados durante a coleta. Por último apareceu o Twitter com 12 perfis oficiais ativos. Entre os tipos de deficiência dos atletas a maioria apresenta do tipo física, sendo quatro com deficiência visual e uma do tipo intelectual.

As coletas nas redes dos atletas iniciaram em dias diferentes, tendo em vista que os dados eram computados apenas conforme 0 atleta atingia uma fase classificatória com chances de medalha. Desse modo, a partir do dia 11 de setembro de 2016 foi possível ter uma coleta que englobasse por completo todos os atletas que constituíram o corpus da pesquisa. Para visualização do somatório total de seguidores por redes de todos os atletas foi elaborado o gráfico 1, onde observa-se o Facebook como a rede com mais seguidores entre os atletas Paralímpicos (cerca de 230 mil), seguido pelo Instagram (cerca de 157 mil) e por último o Twitter (cerca de 42 mil). Naturalmente essa discrepância acontece também devido ao Facebook ser a rede mais comum entre atletas coletados. 


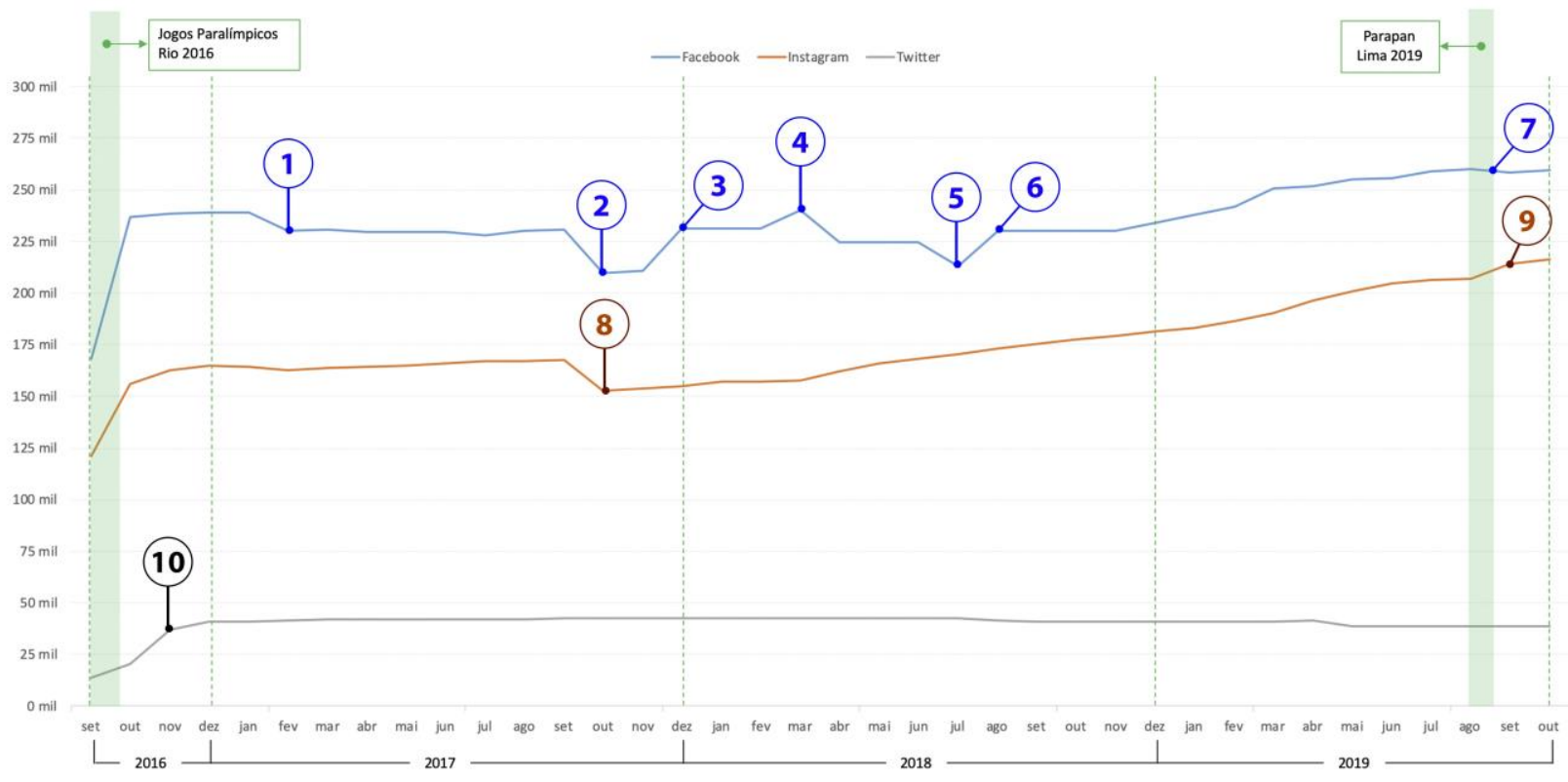

Fonte: Elaborado pelos autores.

Gráfico 1. Somatório da quantidade de seguidores dos atletas Paralímpicos.

Ao analisar o gráfico 1 percebe-se que o período de maior crescimento entre as redes dos atletas analisados ocorreu durante os Jogos Rio 2016. O Twitter foi a rede que se manteve mais estável ao passar do tempo, com um pequeno decréscimo ao final da coleta, enquanto Facebook e Instagram tiveram oscilações, apresentando um crescimento constante a partir de agosto de 2018. Ao observar os possíveis motivos das oscilações no gráfico 1 verificou-se frequentes trocas, encerramentos e reaberturas dos perfis nas redes, onde por alguns atletas concentrarem um número elevado de seguidores, o impacto no somatório total acabou demonstrando uma resposta significativa. A queda encontrada no Facebook em fevereiro de 2017 ocorreu devido ao encerramento da fanpage do atleta Clodoaldo Silva (gráfico 1:1), que, posteriormente, em março de 2018, migrou da página "@tubaraoolimpico" para "@clodoaldosilvaoficial" (gráfico 1:4). Em outubro de 2017, Terezinha Guilhermina teve seus perfis oficiais no Facebook (gráfico 1:2) e Instagram (gráfico 1:8) encerrados, gerando links de acesso inexistentes. 0 mesmo aconteceu com o perfil no Instagram de Verônica Almeida no mesmo período (gráfico 1:8). Contudo, em dezembro de 2017 Terezinha Guilhermina reativou um novo perfil oficial no Facebook (gráfico 1:3). 0 atleta Lucas Prado teve seu perfil oficial no Facebook encerrado em julho de 2018 (gráfico 1:5). No mês de agosto 2018 a Fanpage de Terezinha Guilhermina retornou (gráfico 1:6). Também foi possível visualizar um crescimento no Twitter, no mês de outubro de 2016 (gráfico 1:10), que ocorreu devido a um aumento dos seguidores nos perfis dos atletas Edênia Garcia (que cresceu 1.938 seguidores) e Alex Pires (que cresceu 922 seguidores).

Durante o Parapan 2019, entre os meses de agosto e outubro de 2019, observou-se uma diferença de evolução das redes com um leve decréscimo do Facebook (gráfico 1:7) enquanto o Instagram teve um incremento (gráfico 1:9). Possivelmente, essa variação pode ser explicada pelo fechamento do perfil de Antônio Tenório (gráfico 1:7). Mesmo assim, após o Parapan 2019, o total de seguidores no Facebook subiu $913(0,35 \%)$, totalizando 259.304 , e no Instagram 2.044 (.95\%) totalizando 216.159.

O impacto que alguns perfis tiveram no montante total de seguidores entre os atletas analisados pode ser explicado devido ao fato de que os 5 perfis com mais seguidores equivalem a $60,7 \%$ do total analisado, e 
os 10 principais representam $85,1 \%$, conforme quadro 2. Também se notou que o Facebook foi a rede com mais seguidores, seguida pelo Instagram e tendo o Twitter com um volume consideravelmente menor na última posição.

Quadro 2. Atletas Paralímpicos com mais seguidores em outubro de 2019.

\begin{tabular}{|c|c|c|c|c|c|c|}
\hline & Atleta (posição Rio 2016) & Facebook & Instagram & Twitter & TOTAL & $\%$ Total \\
\hline 1 & Daniel Dias $\left(1^{\circ}\right)$ & 49.128 & 65.500 & 9.617 & 124.245 & $24.2 \%$ \\
\hline 2 & Clodoaldo Silva $\left(2^{\circ}\right)$ & 42.046 & 18.900 & 0 & 60.946 & $11.8 \%$ \\
\hline 3 & Verônica Hipólito $\left(2^{\circ}\right)$ & 27.093 & 22.600 & 2.739 & 52.432 & $10.2 \%$ \\
\hline 4 & ${\text { Yohansson do Nascimento }\left(2^{\circ}\right)}^{\circ}$ & 25.547 & 14.200 & 0 & 39.747 & $7.7 \%$ \\
\hline 5 & Alan Fonteles $\left(2^{\circ}\right)$ & 29.703 & 4.967 & 203 & 34.873 & $6.8 \%$ \\
\hline 6 & André Brasil $\left(2^{\circ}\right)$ & 12.879 & 12.100 & 3.453 & 28.432 & $5.5 \%$ \\
\hline 7 & Natália Mayara A. da Costa $\left(16^{\circ}\right)$ & 9.285 & 14.400 & 4.099 & 27.784 & $5.4 \%$ \\
\hline 8 & Alex Pires $\left(16^{\circ}\right)$ & 3.430 & 17.900 & 3.289 & 24.619 & $4.8 \%$ \\
\hline 9 & Edênia Garcia $\left(2^{\circ}\right)$ & 6.972 & 6.682 & 10.900 & 24.554 & $4.8 \%$ \\
\hline 10 & Terezinha Guilhermina $\left(3^{\circ}\right)$ & 17.612 & 2.541 & 0 & 20.153 & $3.9 \%$ \\
\hline & TOTAL & 223.695 & 179.790 & 34.300 & 437.785 & $85.1 \%$ \\
\hline
\end{tabular}

Fonte: Elaborado pelos autores.

O quadro 3 apresenta os atletas que tiveram os maiores índices de crescimento no somatório total das redes ao longo do período analisado. Ao total a média de crescimento de todas as redes foi de $69,7 \%$, sendo que o Facebook cresceu $61 \%$, o Instagram $52,8 \%$ e o Twitter $55 \%$.

Quadro 3. Atletas Paralímpicos com mais crescimento nas redes entre 2016 e 2019.

\begin{tabular}{|c|c|c|c|c|c|}
\hline & Atleta (colocação final Rio 2016) & Facebook & Instagram & Twitter & TOTAL \\
\hline 1 & Petrucio Ferreira $\left(1^{\circ}\right)$ & $98.0 \%$ & $.0 \%$ & $.0 \%$ & $98.0 \%$ \\
\hline 2 & Alex Pires $\left(16^{\circ}\right)$ & $38.2 \%$ & $91.9 \%$ & $91.3 \%$ & $84.3 \%$ \\
\hline 3 & Clodoaldo Silva $\left(2^{\circ}\right)$ & $83.4 \%$ & $87.2 \%$ & $.0 \%$ & $82.7 \%$ \\
\hline 4 & Daniel Tavares Martins $\left(1^{\circ}\right)$ & $83.8 \%$ & $73.0 \%$ & $.0 \%$ & $79.0 \%$ \\
\hline 5 & Natália Mayara A. da Costa $\left(16^{\circ}\right)$ & $55.6 \%$ & $67.9 \%$ & $92.0 \%$ & $67.3 \%$ \\
\hline 6 & Daniel Dias $\left(1^{\circ}\right)$ & $55.3 \%$ & $76.8 \%$ & $49.3 \%$ & $66.2 \%$ \\
\hline 7 & Phelipe Rodrigues $\left(3^{\circ}\right)$ & $29.1 \%$ & $70.3 \%$ & $84.3 \%$ & $62.6 \%$ \\
\hline 8 & Verônica Hipólito $\left(2^{\circ}\right)$ & $88.0 \%$ & $14.6 \%$ & $93.1 \%$ & $56.7 \%$ \\
\hline 9 & Yohansson do Nascimento $\left(2^{\circ}\right)$ & $73.3 \%$ & $8.5 \%$ & $.0 \%$ & $50.1 \%$ \\
\hline 10 & Edênia Garcia $\left(2^{\circ}\right)$ & $5.3 \%$ & $38.1 \%$ & $84.9 \%$ & $49.6 \%$ \\
\hline & MÉDIA DE CRESCIMENTO & $61.0 \%$ & $52.8 \%$ & $55.0 \%$ & $69.7 \%$ \\
\hline
\end{tabular}

Fonte: Elaborado pelos autores.

Foi possivel verificar que os atletas medalhistas de ouro tiveram os maiores percentuais de crescimento nas redes, o que infere a possível influência da conquista de uma medalha olímpica no crescimento da quantidade de seguidores nos perfis dos atletas. Contudo, cabe ressaltar também a presença de dois atletas que não conquistaram medalhas Olímpicas nos Jogos Rio 2016, Alex Pires e Natália Costa, sendo esse um ponto para uma futura análise qualitativa a fim de aprofundar os possíveis fatores para esse crescimento.

Além disso, foram realizados contatos via mensagem no Instagram com treze atletas mais ativos nas redes sociais, visando esclarecer como suas contas eram administradas, se gerenciadas pelos próprios atletas ou 
por alguma assessoria de comunicação. Ao total foram obtidas sete respostas. 0 atleta Alex Pires informou que teve, por um curto momento, assessoria apenas no Facebook, entretanto não informou qual o período; Daniel Dias disse que quem gerencia atualmente suas redes é sua própria empresa de marketing esportivo (Drad Sports), contudo, de acordo com uma postagem do próprio atleta, a empresa iniciou suas atividades em 20181. Daniel Tavares respondeu que tem seu perfil administrado por uma empresa de comunicação chamada Mustache. $O$ perfil de Clodoaldo Silva respondeu que é assessorado há um ano pela empresa Hasse Talentos, sendo esse ex-atleta, aposentado após os Jogos Rio $2016^{2}$ e comentarista no Parapan $2019^{3}$. Já os perfis de Phelipe Rodrigues são gerenciados em conjunto com uma profissional autônoma de assessoria de comunicação. Esses dois perfis foram os que demonstraram mais agilidade e disponibilidade para responder os contatos realizados. As atletas Terezinha Guilhermina e Edênia Garcia responderam que elas mesmas gerenciam seus perfis oficiais. Não visualizaram as mensagens enviadas: Alan Fonteles, André Brasil, Natalia Mayara, Petrucio Ferreira, Verônica Hipolito e Yohansson do Nascimento.

\section{DISCUSSÃO}

Diferentemente dos atletas Olímpicos que tiveram o Instagram como principal plataforma (Teixeira, 2017), para os atletas Paralímpicos a rede que apresentou maior potencial de crescimento foi o Facebook. Possivelmente esse fato possa ser explicado pelo fato dessa rede ser considerada, entre as analisadas, a plataforma mais híbrida, apresentando possibilidades de postagens variadas, com textos, imagens, vídeos, compartilhamentos, etc. Nesse sentido, é possível considerar que, em comparação ao Facebook, as outras plataformas são "menos flexíveis" no que tange a variedade de tipos de conteúdo a serem postados. 0 Instagram tem como foco principal postagens visuais e estéticas, com imagens, fotos e vídeos, já o Twitter enfatiza prioritariamente conteúdos de caráter textual. É possível inferir que a peculiaridade das ferramentas possa de algum modo limitar ou dificultar sua utilização com pessoas que possuam algum tipo de deficiência.

Em contrapartida, fica possivel identificar que a conquista de uma medalha Paralímpica tem um impacto significativo dentro do crescimento do número de seguidores nos perfis oficiais. Tais resultados, apontam que a utilização adequada das redes sociais, aliada ao desempenho esportivo, pode vir a gerar resultados relevantes do ponto de vista de exposição da imagem dos atletas Paralímpicos dentro das redes sociais. Esse fenômeno de crescimento também é notório e pode ser influenciador do crescimento no número de seguidores nas redes sociais, visto que os meios de comunicação em massa parecem dar maior ênfase aos medalhistas Paralímpicos no momento de suas conquistas (Marques et al., 2014). Com os dados apresentados também foi possível considerar um impacto reduzido, ao comparar o crescimento das redes sociais durante as competições, do Parapan em relação aos Jogos Paralímpicos.

Além disso, a aproximação do Comitê Paralímpico Brasileiro com os meios de comunicação em massa, para divulgar o Movimento Paralímpico no Brasil, provavelmente pode ter influenciado a ascensão dos atletas Paralímpicos nas redes sociais (Santos et al., 2019). O próprio aumento da cobertura dos Jogos Paralímpicos Rio 2016. Quando comparado com Londres 2012, teve um impacto significativo, possivelmente explicado pelo fato do Brasil sediar os Jogos. Sendo assim, acredita-se que essa também é uma explicação plausivel para tal movimento nas redes sociais.

\footnotetext{
1 Postagem no perfil oficial do Facebook de Daniel Dias, disponível em: < https://www.facebook.com/danieldias.esp.br/photos/a.545007515549157/1538642696185629>. Acesso em: 21 out. 2019.

2 Clodoaldo Silva confirma aposentadoria após 20 anos de competições. Disponível em: < http://agenciabrasil.ebc.com.br/rio2016/noticia/2016-09/clodoaldo-silva-confirma-aposentadoria-apos-20-anos-de-competicoes>. Acesso em: 23 out. 2019.

3 Clodoaldo Silva vai comentar natação do Parapan no SporTV. Disponível em: < https://sportv.globo.com/site/blogs/blog-docoach/post/2019/08/21/clodoaldo-silva-vai-comentar-natacao-do-parapan-no-sportv.ghtml>. Acesso em: 23 out. 2019.
} 
Importante ainda destacar que a maioria dos atletas pesquisados representam as modalidades Paralímpicas mais populares no Brasil: natação e atletismo. Tais modalidades vêm arrecadando medalhas e regularmente tendo representantes brasileiros nos megaeventos esportivos desde Barcelona 1992. Esse dado corrobora com a pesquisa de Santos et al. (2019) que menciona que das reportagens da Folha de S. Paulo, realizadas sobre os Jogos Paralímpicos, houve um destaque para as modalidades de natação e atletismo, devido a um maior número de medalhas conquistado por esses atletas. Ademais, são essas modalidades que recebem o maior capital econômico e político, sendo privilegiados por financiamentos (Santos et al., 2019). Destacase ainda que, entre as deficiências que participam dos Jogos (intelectual, física e visual), a predominância de atletas nas redes sociais é dos que apresentam deficiência de caráter físico. No que tange a deficiência intelectual, pode-se pensar nessa situação, pelo fato desse tipo de deficiência não estar presente nos Jogos de 2004 e 2008, sendo pouco especulado e contemplado na crescente ascensão do movimento Paralímpico no Brasil (Mello; Winckler, 2012).

No caso da deficiência visual, o baixo número de atletas com redes sociais poderia ser explicado pelas limitações da própria deficiência, como também pela falta de investimento nesse contexto esportivo, o qual viabilizaria a contratação de uma assessoria de comunicação. Sendo as redes sociais com estímulos predominantemente visuais, com a utilização de recursos de imagem, escrita e símbolos, parece ser esse um recurso pouco favorável para um indivíduo com deficiência visual administrar sem auxílio.

Nesse sentido, a questão do profissionalismo na gestão das redes também parece ser importante para um entendimento de seu desempenho. Independentemente de serem ou não administradas com algum tipo de assessoria profissional, parece haver uma utilização de forma equivocada dessas mídias, não dando a devida atenção para elas. De certo modo, isso pôde ser verificado a partir do baixo índice de retorno das mensagens, ou até mesmo de visualização das mensagens enviadas. Contudo, cabe reforçar a necessidade do desenvolvimento de outros aprofundamentos de pesquisa para compreender melhor a utilização dessas plataformas, que não foi o enfoque do atual estudo.

\section{CONSIDERAÇÕES FINAIS}

Logo, os resultados encontrados indicam a existência de uma gama de fatores que podem influenciar diretamente na exposição dos atletas nas mídias digitais entre eles: os resultados e colocações nas competições; a exposição e relevância das competições em si; o uso adequado e contínuo das redes digitais sociais; o apoio e ampliação econômica da imagem dos atletas pelos próprios Comitês, assim como os meios de comunicação; entre outros. Além disso, é importante destacar a falta de investimento, tanto na capacitação de profissionais, assim como no incentivo e patrocínio ao esporte paralímpico e aos atletas. Nesse sentido, pode-se pensar que o fator financeiro reflete na manutenção das mídias sociais (Marques et al, 2013).

Evidentemente os dados e análises apresentados se referem a uma pequena amostra, não podendo expressar um comportamento global. Todavia, esses indícios iniciais apresentados demonstram a riqueza e necessidade de pesquisas mais aprofundadas dentro desse tema, com ampliação de coletas, por meio de outros dados possíveis de serem coletados (curtidas, comentários, postagens, conteúdos, etc.), assim como de análises priorizando um viés mais qualitativo. 


\section{REFERÊNCIAS}

Araújo, P. F. (2011). Desporto Adaptado do Brasil. São Paulo: Phorte. 216p.

Comitê Paralímpico Brasileiro. (2016). Comitê Paralímpico Brasileiro convoca 278 atletas para os Jogos Paralímpicos Rio 2016. < http://cpb.org.br/noticia/detalhe/2194/comite-paralimpico-brasileiroconvoca-278-atletas-para-os-jogos-paralimpicos-rio-2016>. Acesso em: 28 fev. 2018.

Comitê Paralímpico Internacional. (2016). Rio 2016 Paralympic Games. Disponível em: < https://www.paralympic.org/rio-2016>. Acesso em: 28 fev. 2018.

Figueiredo, T. H. (2014). Gênero e Deficiência: uma análise da cobertura fotográfica dos jogos paralímpicos de 2012. Estudos em Jornalismo e Mídia, 11(2), 484-497. https://doi.org/10.5007/19846924.2014v11n2p484

Greguol, M.; Costa, R. F. (2019). Atividade Física Adaptada: qualidade de vida para pessoas com necessidades especiais. Barueri [SP]: Manole. 608p.

Marques, R. F. R.; Gutierrez, G. L.; Almeida, M. A. B.; Nunomura, M.; Menezes, R. P. (2013). Mídia e 0 movimento paralímpico no Brasil: relações sob o ponto de vista de dirigentes do comitê Paralímpico Brasileiro. Revista Brasileira Educação Física e Esporte, 27(4), 583-596. https://doi.org/10.1590/s1807-55092013000400007

Marques, R. F. R.; Gutierrez, G. L.; Almeida, M. A. B.; Nunomura, M.; Menezes, R. P. (2014). A abordagem midiática sobre o esporte paralímpico: o ponto de vista de atletas brasileiros. Movimento, 20(3), 989-1015. https://doi.org/10.22456/1982-8918.41955

Mello, M. T.; Winckler, C. (2012). Esporte Paralímpico. São Paulo: Editora Atheneu. 254p.

Santos, S. M.; Furtado, S.; Poffo, B. N.; Velasco, A. P.; Souza, D. L. (2019). Mídia e Jogos Paralímpicos no Brasil: a cobertura da Folha de S. Paulo entre 1992 e 2016. Revista Brasileira de Ciências do Esporte, 41(2), 190-197. https://doi.org/10.1016/j.rbce.2018.03.012

Teixeira, C. R. G. (2017). Data fama: o desempenho dos atletas olímpicos nas redes sociais digitais. Dissertação de Mestrado, PUCRS, Porto Alegre, RS, Brasil.

We are social. (2018). Global Digital Report 2018. Disponível em: < https://wearesocial.com/blog/2018/01/global-digital-report-2018>. Acesso em: 21 out. 2019.

We are social. (2019). Global Digital Report 2019. Disponível em: < https://wearesocial.com/globaldigital-report-2019>. Acesso em: 21 out. 2019.

Zoboli, F.; Mezzaroba, C.; Quaranta, A. M.; Correia, E. S. (2016). O corpo Híbrido: análise midiática da participação do atleta Oscar Pistorius no Mundial de atletismo de 2011. Revista Brasileira de Ciências do Esporte, 38(1), 26-33. https://doi.org/10.1016/j.rbce.2015.12.004 